\title{
Article
}

\section{The effect of parental style on bullying and cyber bullying behaviors and the mediating role of peer attachment relationships: A longitudinal study}

Charalampous, Kyriakos, Demetriou, Constantina, Tricha, Loukia, Ioannou, Myria, Georgiou, Stelios, Nikiforou, Militsa and Stavrinides, Panayiotis

Available at http://clok.uclan.ac.uk/21701/

Charalampous, Kyriakos, Demetriou, Constantina, Tricha, Loukia, Ioannou, Myria, Georgiou, Stelios, Nikiforou, Militsa and Stavrinides, Panayiotis (2018) The effect of parental style on bullying and cyber bullying behaviors and the mediating role of peer attachment relationships: A longitudinal study. Journal of Adolescence, 64 . pp. 109-123. ISSN 0140-1971

It is advisable to refer to the publisher's version if you intend to cite from the work. http://dx.doi.org/10.1016/j.adolescence.2018.02.003

For more information about UCLan's research in this area go to http://www.uclan.ac.uk/researchgroups/ and search for <name of research Group>.

For information about Research generally at UCLan please go to http://www.uclan.ac.uk/research/

All outputs in CLoK are protected by Intellectual Property Rights law, including Copyright law. Copyright, IPR and Moral Rights for the works on this site are retained by the individual authors and/or other copyright owners. Terms and conditions for use of this material are defined in the policies page. 
Running head: PARENTAL STYLE, BULLYING/VICTIMIZATION, PEER ATTACHMENT 1

Abstract

The purpose of the present study was the examination of the longitudinal effect of parental style on short-term changes in conventional and cyber forms of bullying/victimization, and the investigation of the mediating role of peer attachment relationships on this effect. The participants were 861 children and adolescents ( $52 \%$ girls, $M_{\text {age }}=11.72$ years) attending Cyprus public institutions. Students provided information during three measurement points. There was a six and a 12 week interval among the three measurement points, respectively. The findings of the study indicated that parenting seems to be a significant predictor of all forms of bullying/victimization, conventional and cyber, in early adolescents, even when accounting for bullying/victimization levels eighteen weeks back. More importantly, results showed that the effect of parental style on bullying forms was mediated by peer attachment relationships. Results are discussed in the light of theoretical and practical implications.

Keywords: Parental style, bullying, cyberbullying, victimization, cybervictimization, peer attachment 
The effect of parental style on bullying and cyber bullying behaviors and the mediating role of peer attachment relationships: A longitudinal study

Earlier studies have documented the effect of parental style on early adolescents' involvement in various bullying/victimization behaviors including both conventional and cyber forms (Chen, Ho, \& Lwin, 2016; Lereya, Samara, \& Wolke, 2013). However, adolescence is a period where friendships and peer support are essential, and in which youths seek autonomy from their caregivers and turn to their friends and peers for social support (Hong \& Espelage, 2012; Wilkinson, 2004). A number of studies have supported that peer attachment relationships are both affected by parental style and in return play a significant part in youths' engagement in bullying/victimization. However, no study has investigated a model featuring the potential mediational role of peer attachment relationships regarding the effect of parental style on youths' engagement in conventional and cyber forms of bullying and victimization. Such a model would allow us to gain a better understanding of the pathways through which different parental styles affect adolescents' engagement in various forms of bullying/victimization, and would assist in delineating the potential significance of the peer attachment relationships, as the major path through which parental styles actually affect youths' engagement in bullying/victimization behaviors.

\section{Bullying/Victimization and Cyber Bullying/Victimization}

Olweus (1993) defined bullying as an intentional, systematic and aggressive behavior that is characterized by an imbalance of power between bullies and victims. Bullying has been identified widely in school settings, causing externalizing problems, such as aggressive and antisocial behavior and internalizing ones, such as depression, anxiety and poorer self-esteem to perpetrators and victims, alike (Kaltiala-Heino, Rimpelä, Rantanen, \& Rimpelä, 2000; Olweus, 1993; Sourander, Helstela, Helenius, \& Piha, 2000).

Cyberbullying can be seen as an extension of conventional bullying, which involves the use of electronic devices, such as computers and mobile phones, in order to carry out bullying (Smith et al., 2008). Cyber bullying manifests as a series of repeated hostile behaviors by an individual or a 
group aiming to harm others, e.g., harassment, denigration, outing and exclusion (Li, 2007; Riebel, Jager \& Fischer, 2009). In some instances, cyber bullying may be more hurtful than conventional bullying due to greater public exposure via social media and humiliating websites or deliberate derogatory instant messaging, especially since youths use cyber space to improve social standing and to gain acceptance (Kowalski \& Limber 2007; Mark \& Ratliffe, 2011).

\section{Parental styles}

Parental style plays a crucial role in determining children's and adolescents' behaviour, since the extent to which children are endorsed to negotiate within the family boundaries along with parental support and involvement, strongly influences their development (Wilmshurst, 2008). Parental style (Baumrind, 1991; Maccoby \& Martin, 1983) describes how children perceive their parents' socialization practices such as the way they respond to their needs (responsiveness) and the way they use control (demandingness). These two dimensions are still used in classifying parents in either of the four distinct parental styles, each one revealing different attitudes, values, practices and behaviours: (1) The authoritative style where parents set clear rules and boundaries, but in a democratic environment open to discussion (high demandingness and high responsiveness), (2) the authoritarian style where parents, similarly to authoritative, have high expectations of their children but at the same time expect the child to follow the rules uncritically and they are trying to control child's behavior even through punishment (high demandingness and low responsiveness), (3) the permissive style, in which parents tend to be more responsive towards the child than demanding (low demandingness and high responsiveness) and (4) the neglectful style, in which parents show little or no responsiveness towards their children (low demandingness and low responsiveness).

\section{Parental style and bullying/victimization}

Research concerning parental styles has indicated the presence of strong associations between parental style and various forms of bullying/victimization in children and adolescents (Dehue, Bolman, Vollink, \& Pouwelse, 2012; Georgiou, 2008; Rajendran, Kruszewski, \& Halperin, 2016). For example, in two recent meta-analysis studies (Chen et al., 2016; Lereya et al., 2013) the 
findings supported that specific parental styles and practices act either as protective or as risk factors concerning both conventional and cyber forms of bullying and victimization. According to previous findings, the permissive parental style best predicts bullying and victimization (Gomez-Ortiz, Del Rey, Casas, \& Ortega-Ruiz, 2014), yet such a style seems to relate more strongly with victimization than bullying (Baldry \& Farrington, 2007; Kaufmann, et al., 2000). In addition, children of permissive parents are vulnerable to cyberbullying involvement, as they are exposed to cyber space without supervision (Dehue et al., 2012). According to Georgiou (2008), permissive parents may be overprotective and as a consequence, they do not let their children to develop basic social skills. As a result, children might become dependent on their parents and they cannot defend themselves in peer victimization instances.

Engagement in bullying and victimization, also seems to be affected by authoritarian parenting. Bullying seems to have a stronger relation with authoritarian parenting than victimization (Baldry \& Farrington, 2000; Bowes et al., 2009; Ok \& Aslan, 2010; Stavrinides, Nikiforou, \& Georgiou, 2015). Furthermore, authoritarian parental style is also closely related to both cyberbullying and cybervictimization (Dilmac \& Aydogan, 2010; Floros et al., 2013; MakriBotsari, \& Karagianni, 2014; Valcke, Bonte, De Wever, \& Rots, 2010). According to Patterson $(1982,1986)$ the daily interactions in the family environment are very important for children, who learn to be aggressive towards less powerful others, by watching these interactions of their family members. In the case of authoritarian parents, punitive and harsh practices are applied to their children, whereas they are not responsive to their children's needs. On the other hand, research has consistently indicated that authoritative/flexible parenting is a protective factor for both conventional and cyber forms of bullying/victimization (Baldry \& Farrington, 2005; Fanti, Demetriou, \& Hawa, 2012; Kokkinos, Antoniadou, Asdre \& Voulgaridou , 2016; Rajendran et al., 2016; Wang, Iannotti, \& Nansel, 2009).

\section{Peer attachment}


Attachment was originally defined as the strong affective bond established between the infant and the primary caregiver (generally the mother) (Bowlby, 1973; 1982). However, over the years, the term has broaden to include other significant relationships, such as those with peers (Armsden \& Greenberg, 1987; Laible, Carlo, \& Raffaelli, 2000). Nickerson and Nagle (2005) suggest that peer attachment is a deep bond, which occurs when children internalize the knowledge that a peer will be available and responsive during times of distress.

The attachment relationship can be conceptualised in the form of a continuum of emotional regulation for managing affect, events and relationships (Jacobite \& Hazen, 1999). At the one end of the continuum is the anxious-avoidant attachment relationship, for which over-emphasis is placed on controlling and minimising affect whereas, at the opposite end, there lies the anxiousresistant style which is characterised by relatively uncontrolled, poorly-managed affect. Secure attachment constitutes the equilibrium between the two extremes of emotional regulation.

\section{Peer attachment and bullying/victimization}

A number of studies have supported that peer relationships may influence the children's involvement in bullying and victimization (Georgiou, 2008; Shetgiri, Lin, Avila, \& Flores, 2012; Knous-Westfall, Ehrensaft, Watson-MacDonell, \& Cohen, 2012; Nikiforou, Georgiou, \& Stavrinides, 2013). Additionally, several studies suggest that peer rejection and lack of supportive friends relate to victimization. That is, children's negative perceptions of relationships with classmates increases the possibility of victimization (Bacchini, Esposito, \& Affuso, 2009; Sukkyung, Furlong, Felix, Sharkey, \& Tanigawa, 2008), while friendships and support by peers act protectively against victimization (Hodges, Malone, \& Perry, 1997). On the other hand, other studies suggest that negative peer influence, such as damaging or destroying property, participating in gang activities and fighting is related to children's involvement in bullying incidents (e.g. Espelage, Bosworth, \& Simon, 2000). Peer relationships play an important role on children's socialization process. James and Owens (2005) found that victimization is perceived as a form of 
manipulation and maintenance of peer relations. Therefore, supporting peer relationships can act as a protective factor against bullying and victimization.

On the same vain, although limited studies have dealt with this issue, a similar relationship seems to be in place between peer attachment and cyberbullying and cybervictimization (Burton, Florell, \& Wygant, 2013; Wright et al., 2015). Specifically, Wright, et al. (2015) indicated that cybervictims had lower levels of peer attachment than cyberbullies and that uninvolved adolescents reported greater peer attachment when compared to all three cyberbullies, cybervictims and cyberbully-victims.

\section{Parental Styles and Peer Attachment Relationships}

The existing research on the relationship between parental styles and peer attachment is grounded on attachment theory and the hypothesis that the degree of security felt in the relationship between children and their parents forms the internal working model that informs children's peer relationships (Ladd \& Pettit, 2002). Similarly, social cognition theory posits that children form what they define as schemes or scripts regarding relationships; that is, relational styles that children learn, follow and modify as they accumulate with their experiences with parents, peers, teachers, and significant others (Mize \& Ladd, 1988). Even though there is a considerable amount of empirical research on aspects of parenting practices and peer relationships, there are very few studies on parental styles and peer attachment relationships despite strong associations that have been reported (e.g., Bank, Burraston \& Snyder, 2004; Kim, Seo, Kim, \& Kim, 2012). In a recent study, Safdar and Zahrah (2016) investigated a sample of 284 adolescents aged 13 to 16 years old to examine the relationship between parental styles and peer attachment using the Parental Authority Questionnaire and the Inventory for Parent and Peer Attachment. Their findings supported the presence of strong associations among parental styles and peer attachment relationships. For example, Authoritative parenting alone accounted for the $40.7 \%$ of the degree of Communication and Trust found in peer relationships. 
Some authors however, have been critical about research linking parenting and peer attachment (Ladd \& Pettit, 2002). For example, Brown and Bakken (2011) note that although this line of research seems coherent, since studies come from a common theoretical background, the absence of sufficient research investigating longitudinal and reciprocal relationships between parental styles and peer attachment limits our understandings of the causal paths among the two constructs.

\section{Parental style, peer attachment relationships and bullying/victimization}

The transition from childhood to early adolescence results in a dramatic shift of the social needs of children, as they now seek autonomy from their caregivers and turn to their friends and peers for social support (Hong \& Espelage, 2012; Nickerson \& Nagle, 2005). In fact, by middle adolescence close friends become the major source of intimacy and disclosure and are key providers of both emotional and social support (Wilkinson, 2004) and sometimes they serve as the primary attachment figure. Considering (a) these developmental processes; (b) the close relationship among peer attachment, parental styles and bullying/victimization forms, (c) the time precedence of parental styles over peer attachment relationships, and (d) the indicative influence of peer relationships on the effect of the parental relationship on students' internalizing and externalizing problems; it is hypothesized that by early adolescence, the effect of parental style on conventional and cyber forms of bullying and victimization might be to some extent mediated by peer attachment relationships.

Based on previous research, whereas the relations among parental style, peer attachment relationships, and conventional and cyber forms of bullying/victimization have been widely examined in the past, limited studies have attempted to examine the inter-relations of all three sets of variables at once (van der Watt, 2014). In one such study, Kokkinos (2007) examined the simultaneous effect of parenting and peer attachment on conventional bullying and victimization in elementary students. The results of the study showed that for this age-group insecure attachment 
styles (ambivalent and avoidant) significantly predicted bullying and victimization experiences, over and beyond students' characteristics and attachment style.

A number of studies have also examined the interplay of peer relationships and parenting with respect to early adolescents' internalizing and externalizing problems. Lansford, Criss, Pettit, Dodge, and Bates (2003) for example, conducted a longitudinal study examining the moderating role of the quality of peer relationships and perceived peer antisocial behavior on the link between negative parenting and externalizing behavior problems. Results indicated that peer relations strongly influenced the effect of parenting on externalizing problems. Additionally, Rubin et al. (2004) examined the main and the interactive effect of the relationship with parents and friends on psychosocial functioning in fifth-grade students. Among other things, results showed that high friendship quality buffered the effects of low maternal support on girls' internalizing difficulties. Thus, it is evident that peer relationships seem to influence the effect of the parental relationship on students' internalizing and externalizing problems.

\section{Gender and age differences regarding peer attachment and bullying/victimization}

When studying close relationships, it is crucial to consider the ways in which males and females, and adolescents and early adolescents differ. The literature supports that different behavioral patterns seem to be present for each gender (Cross \& Madson, 1997), and as students move into adolescence progressive differentiation and diversification of the attachment behavioral system takes place (Allen, 2008).

Gorrese and Ruggieri (2012), conducted a meta-analytic study of 54 studies reporting gender differences and 19 studies reporting age differences concerning peer attachment. The findings revealed that females were considerably more securely attached to their peers, and that the age-effect was not significant for both overall attachment and for specific attachment dimensions.

With regards to age differences concerning peer attachment, Gallego et al., (2011) suggested a positive association between age and attachment. Specifically, the authors argued that individuals who experienced secured parental attachment style during the childhood years are more likely to be 
experiencing secured peer attachment during their transition to adulthood. However, other studies suggest a negative association between age and attachment (e.g., Elmore \& Huebner, 2010).

Most studies investigating bullying report more frequently on boys as perpetrators and victims of bullying. Specifically, boys were found to engage more frequently in physical and direct verbal bullying (Peets \& Kikas, 2006), and in longitudinal trajectory studies, girls have been found to be underrepresented in the high- and moderate-bullying trajectory groups and overrepresented in the never bullying group (Pepler, Jiang, Craig, \& Connolly, 2008). Nonetheless, indirect and relational bullying was found to be equally experienced by boys and girls (Craig, 1998), whereas in some studies relational bullying was found to be experienced to a greater extent by girls (Crick \& Nelson, 2002; Von Marées \& Petermann, 2010). Thus, while boys are most likely to be bullyvictims and experience direct bullying, victimized girls tend to be exposed more to indirect forms of bullying (Storch \& Ledley, 2005; Craig et al., 2009).

Physical bullying is most strongly associated with younger students, as direct and physical forms of bullying are replaced by indirect and relational forms as children grow older, which indicates that bullying is expressed in a more subtle way (von Marées \& Petermann, 2010). In this respect, researchers have supported a typical decrease of physical bullying and victimization and an increase in relational bullying and victimization (Salmivalli \& Kaukianen, 2004; Wang et al., 2016) during adolescence.

With respect to cyber forms of bullying/victimization findings have been somewhat inconsistent. Some studies concluded that boys are more often categorized as perpetrators, while girls are more likely to be cyber-victims (Floros et al., 2013; Li, 2007), whereas other studies found that boys and girls engage equally in cyberbullying and cybervictimization (Tokunaga, 2010; Slonje \& Smith, 2008).

Exploring whether age can be used as a predictor of cyberbullying, Mishna, KhouryKassabri, Gadalla, and Daciuk (2012) found that older students were more likely to be involved in online harassment. This finding was also supported by Festl and Quandt (2014), who argued that 
participation in cyberbullying was higher among older youth because they use the internet more often. However, mixed results are found in relation to age and cybervictimization. For example, while some studies demonstrated lack of association between age and cybervictimization (Smith et al., 2008), others showed a positive association, with higher proportion of victims in older ages (Kowalski \& Limber, 2007).

\section{The present study}

The purpose of the present study was the examination of the longitudinal effect of parental style on short-term changes in conventional and cyber forms of bullying/victimization, and the investigation of the mediating role of peer attachment relationships on this effect, in early adolescent students, while taking into consideration gender and age effects. It is hypothesized that parental style will exert a significant effect on short-term changes in both conventional and cyber forms of bullying/victimization (e.g., Chen et al., 2016; Lereya et al., 2013). Peer attachment relationships are expected to mediate this effect. This mediation hypothesis is based on the developmental processes occurring during the transition from childhood to adolescence (Nickerson \& Nagle, 2005), previous research (Lansford et al., 2003; Rubin et al., 2004), the close relationships and the time precedence between the variables of the examined model (Charalampous et al., 2016; Georgiou, 2008; Kokkinos, 2013).

\section{Methods}

\section{Participants}

The total participants were 868 early adolescents with their age ranging from 10 to 15 years $(M=11.72, S D=1.20)$ and they were attending grades five to eight in Cyprus public elementary (seven) and high schools (five) that were purposefully selected with participating schools being diverse in terms of reported bullying perpetration and urban/rural status, and came from three different prefectures ${ }^{1}$. With respect to gender there were 451 girls (52.0\%) and 410 boys (47.5\%),

\footnotetext{
${ }^{1}$ The Cypriot elementary school comprises grades 1-6 and the junior high school grades 7-9, which is a policy present in many countries (International Bureau of Education, 2008)
} 
while $.01 \%$ of the total sample did not provide gender information. Finally, with respect to parental education as an index of SES, only $2.5 \%$ attended elementary school, $37.95 \%$ finished some form of secondary education, $39.5 \%$ received some form of tertiary education and $19.95 \%$ did not provide data on parental education. The years of education for our sample coincide with that of the general population (e.g., United Nations Development Program, 2016).

Of the total participants 761,755 and 722 participated the three time waves of the study respectively (missing 12.3 to $16.0 \%$ ). T-tests with students missing at $\mathrm{T} 1$ showed no differences in T4 bullying perpetration and victimization levels, and likewise students missing at T4 had no differences in $\mathrm{T} 1$ bullying perpetration and victimization levels.

\section{Instruments}

Conventional bullying/victimization. A revised version of the Bullying and Victimization Questionnaire (BVQ; Olweus, 1993) was used in order to measure the conventional manifestation of these two constructs. The revised version consists of 20 items, ten for measuring victimization ( $\alpha$ $=.83$ to .87 ) and ten bullying $(\alpha=.84$ to .90$)$. All items are scored in a 5-point Likert scale, ranging from 1= "it doesn't apply at all”, to 5 = "it applies a lot". This instrument has been employed in a number of recent studies using a Cypriot sample and the psychometric properties have been consistently supported (Stavrinides, Georgiou, \& Theofanous, 2010; Stavrinides et al., 2015). The BVQ was administered at $\mathrm{T} 1$ and at $\mathrm{T} 3$.

Cyber bullying/victimization. The Personal Experiences Checklist (PECK; Hunt, Peters \& Rapee, 2012) was developed as a multidimensional self-report questionnaire for youth who have experienced bullying, including forms of conventional and cyber- bullying. For the present study, we used the Greek translation of the original cybervictimization subscale which consists of eight items $(\alpha=.76-.93)$ and assesses the experience of being cyberbullied through online networks and mobile phones. We also reversed the subject in those items in order to create eight analogous items that assess the experience of bullying perpetration through online networks and mobile phones $(\alpha=$ $.75-.96)$. All items are scored in a 5-point Likert scale. Answers are given in a five point Likert 
scale (Never/Seldom/Sometimes/Most days/All days) and students in our study answered with the past month as a frame of reference. The PECK was administered at T1 and at T3.

Parental style. The parental style was measured through the Parental Authority Questionnaire (Buri, 1991), a self-report measure that assesses children's perspective concerning their parents' rearing practices that constitute parental style. Based on Baumrind's (1991) taxonomy, the instrument yields three distinct factors and consists of 30 items (ten for each factor): Authoritarian $(\alpha=.84)$, Authoritative $(\alpha=.81)$, and Permissive $(\alpha=.68$, for three items). Items are answered on a five-point Likert-type scale, ranging from $1=$ "strongly disagree» to " $5=$ strongly agree", (10 items for each scale). Earlier studies have shown satisfactory psychometric properties of the PAQ subscales within the Cypriot context (e.g., Georgiou, Stavrinides, \& Fousiani, 2013). The PAQ was administered at T1.

Peer attachment. The 25-item peer attachment subscale of the Greek translation of the revised version of the Inventory of Parent and Peer Attachment (IPPA-R) (Gullone \& Robinson 2005; Charalampous et al., 2016) was used. Based on Bowlby's theory of attachment, the scale assesses three dimensions: degree of mutual Trust and quality of Communication and extent of Alienation and anger. For the present study a 12-item common Trust-Communication factor $(\alpha=$ .92) and a six-item Alienation factor $(\alpha=.66)$, resulted from data analysis. Answers are given on a five-point Likert type scale, ranging from 1 = "Never / Almost never" to 5 = "Always / Almost always". The psychometric properties of the instrument have been supported in the past, with a twofactor structure being supported in early adolescent samples (Charalampous et al., 2016; Hausman, 2012). Whereas IPPA also measures parental attachment that part of the questionnaire was not administered in the present study, as the study focused only on the effect of parenting practices and not that of the child-parent relationship. The IPPA was administered at T3.

\section{Procedure}

Initially, permission was secured from the Cyprus Ministry of Education. Then we contacted the administrators of the 15 high schools and lyceums asking for their participation in the study. 
Members of the research group visited each school and described the goals and the procedure of the study to the participants. Accordingly, we provided each student a letter of consent that at least one parent or legal guardian should sign in order for them to participate. Students were also informed of the survey anonymity protocol, data protection procedures, and their right to withdraw from the study at any time they wished. Upon the return of the consent forms, the three-wave questionnaire administration took place. Students completed the questionnaires during one class hour and returned it to the researchers at that time. The same procedure of administration was followed during the subsequent time points. Time 1 was conducted between the $15^{\text {th }}$ and the $22^{\text {nd }}$ of October, Time 2 between the $10^{\text {th }}$ and the $15^{\text {th }}$ of December, Time 3 between the $1^{\text {st }}$ and $10^{\text {th }}$ of April. Dates and questionnaires for each wave are presented in Table 1.

Table 1.

Administration Waves, Respective Questionnaires Administered and Variables Measured

\begin{tabular}{ccc}
\hline & Administration waves & \\
Time 1 & Time 2 & Time 3 \\
December & January & April \\
& (6 weeks interval from T1) & (12 weeks interval from T2) \\
\hline PAQ & Questionnaires - Variables measured \\
Permissive & IPPA & BVQ \\
Authoritative & Peer Trust & Bullying \\
Authoritarian/Flexible & Peer Communication & Victimization \\
BVQ & Peer Alienation & PECK \\
Bullying & & Cyber bullying \\
Victimization & & Cyber victimization \\
PECK & & \\
Cyber bullying & & \\
Cyber victimization & & \\
\hline
\end{tabular}

\section{Analysis Plan}

The main analysis technique for the present study was structural equation modelling (SEM). The maximum likelihood estimation was used and analyses were performed with the AMOS program (Arbuckle, 2006). Several indices were examined to assess model fit including the chisquared goodness of fit statistic $\left(\chi^{2}\right)$, the Comparative Fit Index (CFI), the Tucker Lewis index (TLI) and the Root Mean Squared Error of Approximation (RMSEA) (Browne \& Cudeck, 1989; 
Byrne, 2009; Hu \& Bentler, 1999; Marsh, Wen, \& Hau, 2004; Smith \& McMillan, 2001). Adequate

fit is indicated by non-significance for the $\chi^{2}$. For the CFI and TLI values over 90 indicate adequate and over .95 indicate excellent fit. Finally, for the RMSEA values less than .08 indicate adequate fit and less than .05 excellent fit.

First, the psychometric properties of the instruments were examined. For the IPPA and the PAQ Exploratory and Confirmatory Factor Analysis (EFA and CFA) were performed to investigate the structural validity of the instruments, whereas for the bullying/victimization and cyber bullying/cyber victimization instruments validation is reported elsewhere (Charalampous, Demetriou, Nikiforou, Tricha, \& Stavrinides, 2017).

Next, structural equation modelling was applied to investigate the mediation hypothesis. Zero-order correlations were initially estimated, followed by the examination of two models (e.g., Baron \& Kenny, 1986): In Model 1 the parental styles were set to load on the four T3 forms of bullying/victimization (bullying, victimization, cyber bullying and cyber victimization). At the same time gender and the four $\mathrm{T} 1$ forms of bullying/victimization were entered as covariates. Model 2 was similar to Model 1 with the addition of the peer attachment variables that served as mediators of the relationship between parental styles and $\mathrm{T} 3$ bullying/victimization variables, i.e. parental styles were set to load on peer attachment variables, which were in return set to load on T3 bullying/victimization variables. Full mediation would be supported in the case that the effect of parental styles on T3 bullying/victimization variables would turn out to be statistically significant in Model 1, and non-significant in Model 2 (or of lower magnitude for partial mediation) and at the same time the effect the parental styles on the mediating variables and that of the mediating variables on T3 bullying/victimization variables in Model 2 would turn out to be statistically significant.

\section{Results}

\section{Psychometric properties}


The psychometric properties of the PAQ questionnaire and the IPPA questionnaires were examined. For this examination the sample was randomly split in half. Sub-sample 1 comprised of 403 participants and sub-sample 2 of 465 . Initially EFA was performed on data from sub-sample 1, the results of which were further examined with data from sub-sample 2, with the application of CFA.

EFA was performed with the use of Principal Axis Factoring (Mor et al. 2008). For the PAQ questionnaire, inspection of the scree plot explicitly indicated the presence of three factors. A subsequent EFA with Principal Axis Factoring using Promax rotation was then performed (e.g. Fabrigar et al. 1999), requesting the extraction of three factors. The rotated component matrix depicted three readily comprehensible factors. These factors were in essence identical to the Permissive, the Authoritarian and the Authoritative/Flexible scales in terms of items. Whereas the Authoritarian and Authoritative/Flexible subscales retained all their items, for the Permissive subscale seven items had low loadings $(<.4)$, and further analyses showed that their inclusion lowered the sub-scales' internal consistency. Given that the three-item Permissive subscale had a Cronbach's alpha value of .68, we decided to proceed these three items (items 6, 19 and 24). EFA results are presented in Appendix A.

CFA was then performed with sub-sample 2. Each of the three parental styles were set to load on their respective items based on the EFA results. Results were indicative of a marginally fitting model $\left[\chi^{2}(227, \mathrm{n}=465)=511.59, p<.001, \chi^{2} / \mathrm{df}=2.25, \mathrm{CFI}=.88, \mathrm{RMSEA}=.052\right]$. Whereas further improvement was feasible, with the insertion of correlated error terms guided by the modification indices, we decided to proceed with the present model in subsequent analysis, based also on the fact the model parameters were in the expected direction associated with reasonable standard errors.

The psychometric properties of the IPPA-R peer were examined next. EFA was performed with the use of Principal Axis Factoring (Mor et al. 2008). Inspection of the scree plot explicitly indicated the presence of two factors. A subsequent EFA with Principal Axis Factoring using 
Promax rotation was then performed (e.g. Fabrigar et al. 1999), requesting the extraction of two factors. The rotated component matrix depicted two readily comprehensible factors. Factor 1 comprised of 12 items that belonged to the Trust and the Communication subscales and Factor 2 comprised of seven items that belonged to the Alienation subscale. A similar analysis with the request of three factors did not result in a meaningful third factor. Thus, we proceeded with the twofactor model. EFA results are presented in Appendix B.

The 19-item two-factor scale was then subjected to maximum likelihood CFA. Results were indicative of an adequately-fitting model $\left[\chi^{2}(151, \mathrm{n}=465)=318.76, p<.001, \chi^{2} / \mathrm{df}=2.11, \mathrm{CFI}=\right.$ .94$, RMSEA $=.056]$. Model parameters were in the expected direction associated with reasonable standard errors.

The descriptive statistics along with the internal consistency for all the variables of the study are presented in Table 2 .

Table 2

Descriptive Statistics regarding the variables of the study, along with Internal Consistency

\begin{tabular}{lcccc}
\hline \multicolumn{1}{c}{ Variable } & Range & $M$ & $S D$ & $\alpha$ \\
\hline T1 Parental Styles & & & & \\
$\quad$ Permissive & $1.00-5.00$ & 2.98 & 1.04 & .68 \\
$\quad$ Authoritarian & $1.00-5.00$ & 2.36 & .83 & .81 \\
$\quad$ Authoritative/Flexible & $1.10-5.00$ & 3.85 & .82 & .84 \\
T2 Peer Attachment & & & & \\
$\quad$ Trust-Communication & $1.00-5.00$ & 3.91 & .89 & .92 \\
Alienation & $1.00-4.71$ & 1.74 & .63 & .66 \\
T1 Forms of bullying/victimization & & & & \\
$\quad$ Bullying & $1.00-5.00$ & 1.30 & .49 & .84 \\
$\quad$ Victimization & $1.00-5.00$ & 1.42 & .56 & .83 \\
$\quad$ Cyber bullying & $1.00-3.17$ & 1.03 & .17 & .75 \\
$\quad$ Cyber victimization & $1.00-3.43$ & 1.08 & .25 & .76 \\
T3 Forms of bullying/victimization & & & & \\
$\quad$ Conventional Bullying & $1.00-5.00$ & 1.26 & .51 & .90 \\
$\quad$ Conventional Victimization & $1.00-5.00$ & 1.35 & .57 & .87 \\
$\quad$ Cyber bullying & $1.00-5.00$ & 1.06 & .35 & .96 \\
$\quad$ Cyber victimization & $1.00-4.43$ & 1.10 & .38 & .93 \\
Demographics & & & & \\
\hline
\end{tabular}




\begin{tabular}{lcccc}
\hline Gender & $1.00-2.00$ & 1.48 & .50 & - \\
$\begin{array}{l}\text { Educational level (elementary / high } \\
\text { school) }\end{array}$ & $1.00-2.00$ & 1.54 & .50 & - \\
\hline
\end{tabular}

Note. $\alpha=$ Cronbach's alpha.

The mediation hypothesis models. The mediation hypothesis of the study was examined next. First, the baseline model was tested. In this model all T1 parental style (Permissive, Authoritative and Flexible) and T2 peer attachment (Trust and Alienation) variables were entered in the model as latent variables based on the CFA models previously examined. The T1 and T3 bullying/victimization forms (conventional bullying/victimization, cyber bullying/victimization) and the demographic (gender and educational level) variables were entered in the model as measured variables. Results supported that the model was a good fit to the data $\left[\chi^{2}(1178, \mathrm{n}=868)\right.$ $\left.=2403.17, p<.001, \chi^{2} / \mathrm{df}=2.04, \mathrm{CFI}=.90, \mathrm{TLI}=.92, \mathrm{RMSEA}=.035\right]$ and model parameters were in the expected direction associated with reasonable standard errors. Zero-order correlations are presented in Table 3. The correlations were in their majority statistically significant, except from the correlations associated with Permissive parenting, which had only two significant correlations. The correlations were generally in the expected direction.

We then proceeded with the examination of Model 1. In this model all parental style variables were set to load on T3 bullying/victimization forms and at the same time T1 bullying/victimization forms, educational level and gender were entered as covariates in the model. Each T1 bullying/victimization form was set to load on its respective T3 form, whereas gender and educational level were set to load on all T3 bullying/victimization forms. The model was shown to be a reasonable fit to the data $\left[\chi^{2}(438, \mathrm{n}=868)=1126.33, p<.001 ; \chi^{2} / \mathrm{df}=2.57, \mathrm{CFI}=.89\right.$, RMSEA $=.043]$ and model parameters were in the expected direction, associated with low standard errors. Model 1 is presented in Figure 1. The Authoritarian parental style positively and the Flexible parenting negatively affected most T3 bullying/victimization forms regardless of the effect of the respective T1 forms. On the other hand, Permissive parenting positively affected only T3 
conventional bullying. Gender had no significant effect on T3 bullying/victimization forms,

whereas educational level positively affected T3 conventional and cyberbullying, and

cybervictimization. The model explained $21,21,11$ and $8 \%$ of the variance for T3 conventional bullying, conventional victimization, cyberbullying and cybervictimization, respectively. 
Table 3.

Zero-order correlations among the variables of the baseline model

\begin{tabular}{|c|c|c|c|c|c|c|c|c|c|c|c|c|c|c|}
\hline & 1 & 2 & 3 & 4 & 5 & 6 & 7 & 8 & 9 & 10 & 11 & 12 & 13 & 14 \\
\hline \multicolumn{15}{|l|}{ (1) T1 Permissive parenting } \\
\hline (2) T1 Authoritarian parenting & - & & & & & & & & & & & & & \\
\hline (3) T1 Flexible parenting & .42 & - & & & & & & & & & & & & \\
\hline (4) T2 Peer Trust & .25 & -.14 & .48 & & & & & & & & & & & \\
\hline (5) T2 Peer Alienation & - & .29 & .30 & -.47 & & & & & & & & & & \\
\hline (6) T1 Conventional Bullying & - & .34 & -.13 & -.22 & .32 & & & & & & & & & \\
\hline (7) T1 Conventional Victimization & - & .27 & -.11 & -.24 & .37 & .47 & & & & & & & & \\
\hline (8) T1 Cyber bullying & - & .17 & - & -.16 & .17 & .41 & .22 & & & & & & & \\
\hline (9) T1 Cyber victimization & - & .18 & - & -.12 & .25 & .33 & .43 & .41 & & & & & & \\
\hline (10) T3 Conventional Bullying & - & .24 & -.18 & -.19 & .44 & .43 & .21 & .26 & .17 & & & & & \\
\hline (11) T3 Conventional Victimization & - & .25 & -.17 & -.27 & .48 & .33 & .43 & .20 & .28 & .63 & & & & \\
\hline (12) T3 Cyber bullying & - & .10 & -.13 & -.10 & .24 & .21 & - & .30 & - & .58 & .38 & & & \\
\hline (13) T3 Cyber victimization & - & .17 & - & -.09 & .30 & .19 & .13 & .12 & .24 & .51 & .54 & .55 & & \\
\hline (14) Gender & - & .21 & -.13 & -.11 & - & .23 & - & .11 & - & .20 & .11 & .12 & - & \\
\hline $\begin{array}{l}\text { (15) Educational level (elementary / } \\
\text { high school) }\end{array}$ & - & - & - & .11 & - & - & -.16 & - & - & .13 & - & .11 & .09 & - \\
\hline
\end{tabular}

Note. Values reported are standardized and significant at the $p<.05$ level. 
Model 2 was next examined. Model 2 was an extension of Model 1 with the addition of T2 peer Trust and T2 peer Alienation, which served as mediators of the effect of T1 parental styles on T3 bullying/victimization forms. Parental style variables were set to load on T2 peer attachment variables, which in return were set to load on T3 bullying/victimization forms. Also, the educational level and gender were set to load on T2 parental styles, while the rest of the model remained the same as Model 1.

Results were indicative of a well-fitting model $\left[\chi^{2}(1198, \mathrm{n}=868)=2491.79, p<.001 ; \chi^{2} / \mathrm{df}\right.$ $=2.08, \mathrm{CFI}=.90, \mathrm{RMSEA}=.035]$ and model parameters were in the expected direction, associated with reasonable standard errors. Model 2 is presented in Figure 2. Results showed that mediation was potentially present. All significant effects from T1 parental style variables on T3 bullying/victimization forms in Model 1 were found to be statistically non-significant in Model 2 . The effect of T1 parenting styles on T3 bullying/victimization forms seemed to be largely replaced by the effect of peer attachment relationships. Peer Alienation had significant positive effects on all four bullying/victimization forms, regardless of the T1 bullying/victimization effects, whereas the Trust-Communication variable had no effect on any bullying/victimization form.

On the other hand, parental styles had significant effects on peer attachment relationships. Permissive and Authoritarian parenting had positive and Flexible parenting had a negative effect on peer Alienation, whereas Flexible parenting had positive and Authoritarian parenting had a negative effect on peer Trust-Communication. Regarding the covariates, students' educational level had a positive significant effect on Alienation, T3 conventional bullying and T3 cyber bullying, and gender had positive significant effects on Trust-Communication, and on T3 conventional and cyber bullying. Gender had negative effect on Alienation and positive effect of T3 bullying, victimization and cyberbullying.

The bootstrap estimates of the indirect effects of parenting styles on bullying forms, through peer Alienation are presented in Table 4 (e.g. Little, Little, Card, Bovaird, Preacher, \& Crandall, 2007; Perera, 2013) 
Table 4

Bootstrap Estimates of the Specific Indirect Effects of Peer Rejection on Emotional Adjustment with Standard Errors, 95\% Confidence Bounds and Statistical Significance Estimates.

\begin{tabular}{|c|c|c|c|c|c|}
\hline \multirow{2}{*}{ Effect } & \multirow{2}{*}{$\begin{array}{c}\text { Point } \\
\text { estimate }^{1}\end{array}$} & \multirow{2}{*}{$S E$} & \multicolumn{2}{|c|}{$95 \% C I$} & \multirow{2}{*}{$p$-value } \\
\hline & & & $L B^{l}$ & $U B^{1}$ & \\
\hline Indirect effect of Flex. on Bull. through Al. & -.08 & .18 & -.19 & -.04 & .009 \\
\hline Indirect effect of Flex. on Vict. through Al. & -.11 & .57 & -.24 & .06 & .007 \\
\hline Indirect effect of Flex. on CBull. through Al. & -.04 & .13 & -.13 & -.01 & .012 \\
\hline Indirect effect of Auth. on Bull. through Al. & .04 & .03 & .01 & .09 & .009 \\
\hline Indirect effect of Auth. on Vict. through Al. & .05 & .07 & .02 & .10 & .017 \\
\hline Indirect effect of Auth. on CVict. through Al. & .02 & .04 & .00 & .06 & .039 \\
\hline Indirect effect of Perm. on Bull. through Al. & .02 & .57 & -.01 & .11 & .182 \\
\hline
\end{tabular}

Note . Flex. $=$ Flexible parenting, Auth. $=$ Authoritarian parenting, Perm. $=$ Permissive parenting, Bull. $=$ Bullying, Vict. $=$ Victimization, CBull. $=$ Cyberbullying, CVict. $=$ Cybervictimization, $\mathrm{SE}=$ standard error, $\mathrm{LB}=$ lower bound, $\mathrm{UB}=$ upper bound

${ }^{1}$ Values reported are unstandardized.

These results indeed support the mediation hypothesis. It seems that all the effects of Flexible and Authoritarian parenting on bullying forms in Model 1 are mediated by peer Alienation. However, the mediation hypothesis was not supported for the effect of Permissive parenting on conventional bullying.

Overall, the model explained .24 and $.21 \%$ of the variance in peer Trust and Alienation respectively. Regarding the endogenous variables, the model explained $.39, .34, .20$ and $.18 \%$ of the variance in T3 conventional bullying, conventional victimization, cyber bullying and cyber victimization, respectively.

\section{Discussion}

The purpose of the present study was the examination of the longitudinal effect of parental style on short-term changes in conventional and cyber forms of bullying/victimization, and the investigation of the mediating role of peer attachment relationships on this effect, in early adolescent students, while taking into consideration gender and age effects. 
The findings of the study indicated that parenting seems to be a significant predictor of all forms of bullying/victimization, conventional and cyber, in early adolescents, even when accounting for bullying/victimization levels eighteen weeks earlier. More specifically, and in line with previous studies, authoritarian parenting had a positive effect on bullying, victimization and cybervictimization (Baldry \& Farrington, 2000; Bowes et al., 2009; Makri-Botsari, \& Karagianni, 2014). Authoritarian parents tend to use punitive practices, methods that promote acceptance of physical and psychological violence as a way of dealing with problems and conflicts. In return, these children tend to perceive their parents as insensitive in their own problems, they are unable to develop a sense of empathy towards others and they tend to use inequality and competition as interpersonal strategies, thus becoming more aggressive towards peers (Georgiou, Stavrinides, \& Fousiani, 2013). In addition, authoritarian parents barely discuss internet issues and are not open to dialogue about internet uses and access, a behavior that was found to provoke children to be more unresponsive and offensive to their peers in their online social interactions (Dilmac \& Aydogan, 2010). On the one hand, children of authoritarian parents bully others as an attempt to gain freedom and recognition, characteristics that lack in their relations with their parents (Ybarra \& Mitchell, 2004), and on the other hand, they are more vulnerable in being bullied by others as they get anxious from their parents' behavior and consequently they have diminishing self-esteem, a significant predictor of cyber victimization (Guo, 2016).

Authoritative/Flexible parenting had a significant negative effect on bullying, victimization and cyberbullying, a finding that is also in line with earlier studies (Fanti et al., 2012; Kokkinos, et al., 2016; Rajendran et al., 2016). Parents with democratic practices are able to direct their children to more realistic behaviors, developing respect towards others. Due to the healthy parent-child relationship, children of authoritative parents tend to disclose to their parents incidences of bullying, by asking for help, a factor found to protect them from bullying involvement (Makri-Botsari \& Karagianni, 2014). Children of authoritative parents often feel that their caregivers are able to provide comfort and guidance when they experience distress and that they will help them to deal 
appropriately with bullying and victimization experiences (Hay \& Meldrum, 2010). Likewise, the same pattern is found to apply in cyberspace, where authoritative parents set limits in internet usage and timing but at the same time expect their children to behave in a self-regulated manner (Valcke et al., 2010), a practice that aids in the open communication and acceptance in children's cyber social interactions.

With respect to permissive parenting, this parenting practice had a significant effect only on conventional bullying. Results are in partial accordance with previous findings in that permissive parenting generally seems to relate more to victimization than bullying perpetration. More specifically, having highly responsive (permissive) parents places the child at risk for victimization, as such parents are more frequently characterized by overprotection (Georgiou, 2008), an association that was found to be higher among boys than girls (Finnegan, Hodges \& Perry, 1998). Given the significant modifications that the permissive parenting scale underwent in the statistical analyses and the low reliability reported for the items used, the non-effect of permissive parenting on victimization behaviors needs to be interpreted with caution.

The most significant finding of the present study was the mediation of the effect of parental style on all forms of bullying/victimization from peer attachment. This means that the determining effect of parental style on conventional and cyber forms of bullying and victimization, seems to be channeled to a large extent through peer attachment relationships. More specifically, parental style seems to influence peer attachment relationships, which in return influence early adolescents' involvement in the various forms of bullying and victimization. Thus, attachment relationships constitute a significant pathway through which the parenting effect on bullying/victimization takes place. This indicates that the hypothesized developmental shift of focus from parental to peer relationships during adolescence (Hong \& Espelage, 2012; Nickerson \& Nagle, 2005) might cause the sublte replacement of the parenting effect on bullying/victimization behaviors with that of the peer attachment relationship. The transition from childhood to early adolescence results in a dramatic shift of the social needs of children as they now seek autonomy from their caregivers and 
turn to their friends and peers for social support (Hong \& Espelage, 2012; Nickerson \& Nagle, 2005). Whereas the relations among parental style, peer attachment relationships and bullying/victimization forms, have been widely examined in the past, limited studies have attempted to examine the inter-relations among all three sets of variables at once (van der Watt, 2014), and none has examined the mediating role of peer attachment on the effect of parental styles on bullying/victimization forms. Previous findings have also shown that peer relationships are in position to moderate the effect of the parental relationship on students' internalizing and externalizing problems (Lansford et al., 2003; Rubin et al., 2004).

Another key finding of the present study was that peer Alienation was in effect responsible for the mediation, since peer Trust-Communication had no significant effect on any bullying/victimization form. Peer Alienation on the other hand, was significantly influencing all four forms of bullying/victimization with effects of medium to high magnitude. Earlier studies have shown that peer relationships may influence the children's involvement in bullying and victimization (Georgiou, 2008; Knous-Westfall et al., 2012). On the one hand, negative perceptions of relationships with classmates increases the possibility of an individual to be victimized (Bacchini et al., 2009; Sukkyung et al, 2008), while the lack of friendships and support by peers causes the loss of a strong protective factor against victimization (Hodges et al., 1997). Another possible explanation, might be the strong relationship between aggression and poor peer relations (Card, Srucky, Sawalani, \& Little, 2008), which leads children who are interpersonally rejected to become alienated and attempt to adjust by adopting aggressive behaviours (Leary, Jean, \& Erin, 2006), which in turn could predict bullying involvement (Boulton, Bucci, Hawker, \& Hawker, 2009).

With respect to age and gender, several effects were in place. Older students reported higher on peer Alienation, as well as on conventional and cyberbullying. These results are in line with previous studies (Gallego, Delgado, \& SanchezQueija, 2011), in that attachment relationships 
strengthen with age. In addition, previous studies have also reported increase in cyber forms and in some conventional forms of bullying with age (Mishna et al., 2012; Wang et al., 2016)

Regarding gender effects, girls reported more peer Alienation and less bullying, victimization and cyberbullying. In line with previous studies, these results further support the claim that females are generally more emotionally attached with their peers (Gorrese \& Ruggieri, 2012), and that boys report higher conventional bullying (in terms of physical and direct verbal aggression) (Peets \& Kikas, 2006) and cyber bullying perpetration (Floros et al., 2013; Li, 2007).

The two models examined in the present study explain $21-30 \%$ of the variance of conventional forms of bullying and 8 to $14 \%$ of the variance of cyber forms of bullying. Thus, it seems that even within a short-term interval of 18 weeks, and with initial bullying/victimization levels accounted for, there is significant variance in the various forms of the bullying/victimization unexplained, especially for the cyber ones. Even though it might just be that the exogenous and mediating variables in our models had more impact on conventional forms of bullying/victimization that cyber forms, previous longitudinal studies with yearly time intervals have also given indications that cyber forms of bullying show more fluctuation than conventional forms. For example, in the study of Sumter et al. (2012), a curve line between high cyber victimization and time was indicated, something that was not supported for the high traditional victimization group, indicative of the distinct nature of the two. In addition, Jose et al., (2012) showed that whereas all four variables, conventional bullying, conventional victimization, cyberbullying and cyber victimization, remained stable over time, cyber victimization was considerably less stable than traditional victimization.

Despite its significant contribution the present study bears some limitations. First, all variables of the study were measured through self-report instruments. Whereas internationally accredited questionnaires were used and the psychometric properties were established, complementing the use of quantitative data with interviews or observational data would add to the validity of the findings of the present study. This issue also relates to the threat of common method 
variance (Podsakoff, MacKenzie, Lee, \& Podsakoff, 2003). Secondly, there were some issues with some of the subscales of the questionnaires. For example the Trust and the Communication subscales of the peer attachment questionnaire were merged, but this was supported by an elaborate procedure which evidence strong psychometric properties for the resulting structure. For the Flexible parenting subscale on the other hand, a significant number of items were removed based on the EFA outcomes. This indicates that the items purported to measure the Flexible parenting construct in the present sample might not be appropriate. A better measured Flexible parenting construct might have provided additional information regarding the hypothesized relationships, yet the sophisticated statistical techniques applied in the analyses of the present study proved a safeguard by allowing us to examine complex relationships with confidence in the measurement properties of the variables entering the final models. Moreover, the sample of the present study was not randomly selected but a rather convenience sampling procedure was followed. Nonetheless, every effort was made for diversifying the participants of our study including the participation of schools from different prefectures, schools from urban and rural areas, and schools of differing status in terms of reported bullying problems. Finally, both EFAs and CFAs were performed with Pearson correlation matrix. Considering that the items were measured by a Likert-scale polychoric correlation matrix would be a more appropriate choice (Holgado-Tello, Chacón-Moscoso, Barbero-García, \& Vila-Abad, 2010). Nonetheless, in addition to the stringent split-half EFA CFA procedure that took place in the present study, a five-level Likert measurement scale, such as in our case, while not optimal, is considered at least sufficient for such analyses (e.g., Coenders \& Saris, 1995).

Overall the present study has made some significant contributions. Theoretically, this is probably the first study to thorough investigate the potential mediating role of peer attachment on the effect of parental style on conventional and cyber forms of bullying and victimization. The outcomes of this investigation allowed us to gain a better understanding of the pathways through which different parental styles affect adolescents' engagement in various forms of the 
bullying/victimization phenomenon, and made clear that peer attachment relationship constitutes one such major pathway. Despite previous evidence indicating that peer relationships are in position to moderate the effect of the parental relationship on students' internalizing and externalizing problems (Lansford et al., 2003; Rubin et al., 2004), and even though widely known developmental processes in the transition from childhood to adolescence, highlight the shift of focus from the parental to the peer relationships (Hong \& Espelage, 2012; Nickerson \& Nagle, 2005), this is the first study to examine the mediating role of peer attachments on the effect of parenting on bullying/victimization forms.

At the practical level, considering the mediation of peer attachment relationships, as well as the major impact of peer Alienation compared to that of peer Trust, in mediating parental style effect but also, in influencing bullying/victimization forms, two major practical conclusions can be drawn. First, it is important to acknowledge the importance of parenting on bullying/victimization, but at the same time it is clear that for early adolescents a more direct target of prevention and intervention anti-bullying programs should emphasize peer relations. Secondly, whereas building peer Trust and Communication and peer Alienation seem to be sides of the same coin, the detrimental effect of peer Alienation on all bullying/victimization forms examined in our study seems far more important.

At a methodological standpoint, the present study is one of the first to implement a thorough longitudinal research design, accounting for the initial levels of the endogenous variables, i.e. the bullying/victimization forms. The study also, accounted for the effect of demographic variables such as gender and educational level, and each of the exogenous and mediating variables were measured at different time points. The study also pioneered in taking into perspective a relatively short time interval (18 weeks). The low effect of initial bullying/victimization levels on the final ones, indicates that the fluctuation of bullying/victimization in both its conventional and cyber forms is such that not only allows, but actually warrants such investigations. 
In closing, the present study has made some significant contributions. Nonetheless, it should be noted that in the final models, a considerable amount of variance in bullying/victimization forms, especially cyber ones, remained unexplained. It thus seems possible that for cyber forms of this phenomenon other variables such as biological characteristics (e.g., psychopathic traits), personal beliefs (e.g., moral disengagement), environmental factors (e.g., school climate), might also play a significant role in bullying/victimization short-term fluctuations. Future studies are expected to capitalize on the findings of the present study and extend this line of research by testing further theoretical models explaining the combined influence of social, personal and environmental factors on early adolescents' involvement in bullying/victimization behaviors. 


\section{References}

Arbuckle, J. L. (2006). Amos 7.0 User's Guide. Spring House, PA: Amos Development.

Armsden, G., \& Greenberg, M. (1987). The inventory of parent and peer attachment: Individual differences and their relationship to psychological well-being in adolescence. Journal of youth and adolescence, 16(427).

Bacchini, D., Esposito, G., \& Affuso, G. (2009). Social experience and school bullying. Journal of community \& applied social psychology, 19(1), 17-32.

Baldry, A. C., \& Farrington, D. P. (2000). Bullies and delinquents: Personal characteristics and parental styles. Journal of Community and Applied Social Psychology, 10, 17-31.

Baldry, A. C., \& Farrington, D. P. (2005). Protective factors as moderators of risk factors in adolescence bullying. School Psychology of Education, 8, 263-284.

Baldry, A. C., \& Farrington, D. P. (2007). Effectiveness of programs to prevent school bullying. Victims and Offenders, 2(2), 183-204.

Bank, L., Burraston, B., \& Snyder, J. (2004). Sibling conflict and ineffective parenting as predictors of adolescent boys' antisocial behavior and peer difficulties: Additive and interactional effects. Journal of Research on Adolescence, 14, 99 - 125. 
Baron, R. M., \& Kenny, D. A. (1986). The Moderator-Mediator variable distinction in social psychological research: Conceptual, strategic, and statistical considerations. Journal of Personality and Social Psychology, 51, 1173-1182.

Baumrind, D. (1991). Parenting styles and adolescent development. In J. Brooks-Gunn, R. Lerner, \& A. Petersen (Eds.). The encyclopedia of adolescence (pp.746-758). New York: Garland.

Boulton, M., Bucci, E., Hawker, D., \& Hawker, D. (2009). Swedish and English secondary school pupils' attitudes towards, and conceptions of, bullying: Concurrent links with bully/victim involvement. Scandinavian Journal of Psychology, 40, 277-284.

Bowes, L., Arseneault, L., Maughan, B., Taylor, A., Avshalom, C., \& Terrie, E. M., (2009). School, neighbourhood and family factors are associated with children's bullying involvement: A national representative longitudinal study. Journal of American Academy of Child and Adolescent Psychiatry, 48(5), 545-553.

Bowlby, J. (1973). Attachment and Loss, Vol. 2. Separation: Anxiety and Anger. New York: Basic.

Bowlby, J. (1982). Attachment and Loss, Vol. 1. Attachment. New York: Basic.

Brown, B. B., \& Bakken, J. P. (2011). Parenting and peer relationships: Reinvigorating research on family-peer linkages in adolescence. Journal of Research on Adolescence, 21(1), 153-165. http://doi.org/10.1111/j.1532-7795.2010.00720.x

Browne, B. W., \& Cudeck, R. (1989). Single sample croos-validation indices for covariance structures. Multivariate Behavioral Research, 24, 136-162.

Buri, J. (1991). Parental Authority Questionnaire. Journal of Personality Assessment, 1, 110-119.

Burton, A. K., Florell, D., \& Wygant, D. B. (2013). The Role of Peer Attachment and Normative Beliefs About Aggression on Traditional Bullying and Cyberbulying. Psychology in the Schools, 50(2). 
Byrne, B. M. (2009). Structural equation modelling with AMOS: Basic concepts, applications and programming (2nd Ed.). New York: Routledge Taylor and Francis Group.

Card, N., Srucky, B., Sawalani, G., \& Little, T. (2008). Direct and indirect aggression during childhood and adolescence: A meta- analytic review of gender differences, intercorrelations, and relations to maladjustment. Child development, 79(5), 1185-1229.

Charalampous, K., Demetriou, K., Nikiforou, E., Tricha, L., \& Stavrinides, K. (2017, May). Comparing short-term growth in conventional and cyber forms of bullying in early adolescent students. Paper presented at the World Anti-bullying Forum. Stokcholm, Sweden.

Charalampous, K., Kokkinos, C. M., Apota, E., Iliadou, A., Iosifidou, M., Moysidou, S., \& Vriza, E. (2016). Pre-adolescents representations of multiple attachment relationships: The role of perceived teacher interpersonal behaviour. Learning Environments Research, 19, 63-86. doi: $10.1007 / \mathrm{s} 10984-015-9196-\mathrm{z}$

Chen, L., Ho, S. S., \& Lwin, M. O. (2016). A meta-analysis of factors predicting cyberbullying perpetration and victimization: From the social cognitive and media effects approach. New Media Society, 18, 2 - 20, doi:10.1177/1461444816634037.

Coenders, H ., \& Saris, W . (1 99 5). Categorisation and measurement quality. The choice between Pearson and polychoric correlations. In W .Saris \& A .Munnich (Eds.), The multitraitmultimethod approach to evaluate measurement instruments (pp. 125-144). Budapest: Eötvos University Press

Cohen, J., \& Cohen, P. (1983). Applied multiple correlation/regression analysis for the social sciences (2nd ed.). Hillsdale, NJ: Erlbaum. 
Craig, W. (1998). The relationship among bullying, victimization, depression, anxiety, and aggression in elementary school children. Personality and Individual Differences, 24, 123 130.

Craig, W., Harel-Fisch, Y., Fogel-Grinvald, H., Dostaler, S., Hetland, J., Simons-Morton, B., Molcho, M., de Mato, M.G., Overpeck, M., Due, P., et al. (2009). A Cross-National Profile of Bullying and Victimization among Adolescents in 40 Countries. International Journal of Public Health, 54, 216-224.

Crick, N. R., \& Nelson, D. A. (2002). Relational and physical victimization within friendships: Nobody told me there'd be friends like these. Journal of Abnormal Child Psychology, 30, 599-607.

Cross, S. E., \& Madson, L. (1997). Models of the self: Self-construal theory and gender. Psychological Bulletin, 122, 5-37.

Dehue, F., Bolman, C., Vollink, T., \& Pouwelse, M. (2012). Cyberbullying and traditional bullying in relation to adolescents' perception of parenting. Journal of CyberTherapy \& Rehabilitation, 5(1), 25-34.

Dilmac, B., \& Aydogan, D. (2010). Parental attidutes as a predictor of cyberbullying among primary school children. International Journal of Social, Behavioral, Economics, Bussiness and Industrial Engineering, 4(7), 1667-1671.

Elmore, G. M., \& Huebner, E. S. (2010). Adolescents' satisfaction with school experiences: Relationships with demographics, attachment relationships, and school engagement behavior. Psychology in the Schools, 47, 525-537.

Espelage, D. L., Bosworth, K., \& Simon, T. R. (2000). Examining the social context of bullying behaviors in early adolescence. Journal of Counseling and Development, 78, 326-333.

Fabrigar, L. R., Wegener, D. T., MacCallum, R. C., \& Strahan, E. J. (1999). Evaluating the use of exploratory factor analysis in psychological research. Psychological Methods, 4, 272-299. 
Fanti, K., Demetriou, A. G., \& Hawa, V. V. (2012). A longitudinal study of cyberbullying: Examining risk and protective factors. European Journal of Developmental Psychology, 9 (2), 168-181.

Festl, R., \& Quandt, T. (2014). Cyberbullying at schools: A longitudinal research project. Diskurs Kindheits- und Jugendforschung, 9, 109-114.

Finnegan, R., Hodges, E., \& Perry, D. (1998). Victimization by peers: Association with children's reports of mother-child interaction. Journal of Personality and Social Psychology, 75, 10761086.

Floros, G., Paradeisioti, A., Hadjimarcou M., G. Mappouras, D. G., Kalakouta, O., Avagianou, P., \& Siomos, K. (2013). Cyberbullying in Cyprus - associated parenting styles and psychopathology. Studies in Health Technologies and Informatics, 191, 85-90,

Gallego, I., Delgado, A., \& SanchezQueija, I. (2011). Peer attachment during adolescence and emerging adulthood. Anales De Psicologia, 27, 155-163.

Georgiou, S. (2008). Parental styles and child bullying and victimization experiences at school. Social Psychology of Education, 11(3), 213-227.

Georgiou, S. N., Stavrinides, P., \& Fousiani, K. (2013). Authoritarian parenting, power distance, and bullying propensity. International Journal of School \& Educational Psychology, 1(3), 199-206.

Gomez-Ortiz, O., Del Rey, R., Casas, J. A., \& Ortega-Ruiz, R. (2014). Parenting styles and bullying involvement / Estilos parentales e implicación en bullying. Cultura y Educi\&\#xf3;n: Culture and Education, 26(1), 132-158.

Gorrese, A., \& Ruggieri, R. (2012). Peer Attachment: A Meta-analytic Review of Gender and Age Differences and Associations with Parent Attachment. Journal of Youth and Adolescence, $41(5), 650-72$. 
Gullone, E., \& Robinson, K. (2005). The Inventory of Parent and Peer Attachment - Revised (IPPA-R) for Children: A Psychometric Investigation. Clinical Psychology and Psychotherapy, 12, 67-79.

Guo, S. (2016). A meta-analysis of predictors of cyberbullying perpetration and victimization. Psychology in the Schools, 53(4), 432-453.

Hausman, D. (2012). The factor structure of the Inventory of Parent and Peer Attachment in a clinicreferred sample of anxious Latino youth (Master's thesis). Retrieved from Florida International University Electronic Theses and Dissertations (paper 652).

Hay, C. \& Meldrum, R. (2010). Bullying victimization and adolescent self-harm: Testing hypothesis from general strain theory. Journal of Youth and Adolescence, 39(5), 446-459.

Hodges, E., Malone, M., \& Perry, D. (1997). Individual risk and social risk as interacting determinants of victimization in the peer group. Developmental Psychology, 33(6), 10321039.

Holgado-Tello, F. P., Chacón-Moscoso, S., Barbero-García, I., \& Vila-Abad, E. (2010). Polychoric versus Pearson correlations in exploratory and confirmatory factor analysis of ordinal variables. Quality \& Quantity, 44(1), 153-166.

Hong, J., \& Espelage, D. L. (2012). A Review of Research on Bullying and Peer Victimization in School: An Ecological System Analysis. Aggression and Violent Behavior, 17(4), 311-322.

Hu, L., \& Bentler, P. M. (1999). Cut-off criteria for fit indexes in covariance structure analysis: Conventional criteria versus new alternatives. Structural Equation Modeling, 6, 1-55.

Hunt, C., Peters, L., \& Rapee, R. M. (2012). Development of a Measure of the Experience of Being Bullied in Youth. Psychological Assessment, 24(1), 156-165. 
Jacobite, D., \& Hazen, N. (1999). Developmental pathways from infant disorganization to childhood peer relationships. In J. Cassidy \& P. R. Shaver (Eds.), Handbook of attachment (pp. 671-687). New York: Milford Press.

Jose, P. E., Kljakovic, M., Scheib, E., \& Notter, O. (2012). The joint development of traditional bullying and victimization with cyber bullying and victimization in adolescence. Journal of Research on Adolescence, 22, 301-309.

Kaltiala-Heino, R., Rimpelä, M., Rantanen, P., \& Rimpelä, A. (2000). Bullying at School - An Indicator of Adolescents at Risk for Mental Disorders. Journal of Adolescence, 23, 661-74.

Kaufmann, D., Gesten, E., Lucia, R.C.S., Salcedo, O., Rendina-Gobioff, G., \& Gadd, R., (2000). The relationship between parenting style and children's adjustment: The parents' perspective. Journal of Child and Family Studies, 9(2), 231-245.

Kim, T., Seo, E., Kim, Y. L., \& Kim, D. (2012). The Relationship between Perceived Mother' s Parenting Style, and Peer Relationship Level of an Korean Adolescent child Focused on the moderating effect of gender. GSTF Journal of Law and Social Sciences (JLSS), 1(2), 49-52.

Knous-Westfall, H., Ehrensaft, M., Watson-MacDonell, K., \& Cohen, P. (2012). Parental intimate partner violence, parenting practices, and adolescent peer bullying: a Prospective study. Journal of Child and Family Studies, 21, 754-766.

Kokkinos, C. M. (2007). Elementary school children's involvement in bullying and victimization: The role of attachment style and internalizing and externalizing symptomatology. Scientia Peadagogica Experimentalis, 44(1), 33 - 49.

Kokkinos, C. M. (2013). Bullying and victimization in early adolescence: Associations with attachment style and perceived parenting. Journal of School Violence, 12(2), 174-192. 
Kokkinos, C. M., Antoniadou, N., Asdre, A., \& Voulgaridou, K. (2016). Parenting and Internet behaviour predictors of cyber-bullying and cyber-victimization among pre-adolescents. Deviant Behavior, 37(4), 439-455.

Kowalski, R. M., \& Limber, S. P. (2007). Electronic bullying among middle school students. Journal of Adolescent Health, 41, 22-30.

Ladd, G. W., \& Pettit, G. S. (2002). Parenting and the development of children's peer relationships. Handbook of Parenting Volume 5 Practical Issues in Parenting, 269-309.

Laible, D., Carlo, G., \& Raffaelli, M. (2000). The Differential Relations of Parent and Peer Attachment to Adolescent Adjustment. Journal of Youth and Adolescence, 29(1), 45-59.

Lansford, J. E., Criss, M. M., Pettit, G. S., Dodge, K. A., \& Bates, J. E. (2003). Friendship quality, peer group affiliation, and peer antisocial behavior as moderators of the link between negative parenting and adolescent externalizing behavior. Journal of Research on Adolescence, 13(2), 161-184.

Leary, M., Jean, M., \& Erin, Q. (2006). Interpersonal rejection as a determinant of anger and aggression. Personality and Social Psychology Review, 10(2), 111-132.

Lereya, S. T., Samara M., \& Wolke, D. (2013). Parenting behaviour and the risk of becoming a victim and a bully/victim: A meta-analysis study. Child Abuse \& Neglect, 37, 1091-1108.

Li, Q. (2007). Bullying in the new playground: Research into cyberbullying and cyber victimization. Australasian Research, 23, 435-454.

Little, T. D., Card, N. A., Bovaird, J. A., Preacher, K. J., \& Crandall, C. S. (2007). Structural equation modeling of mediation and moderation with contextual factors. Modeling contextual effects in longitudinal studies, 1, 207-230.

Makri-Botsari, E., \& Karagianni, G. (2014). Cyberbullying in Greek adolescents: The role of parents. Procedia Social and Behavioural Science, 116, 3241-3253. 
Mark, L., \& Ratliffe, K. T. (2011). Cyber worlds: New playgrounds for bullying. Computers in the Schools, 28, 92-116.

Marsh, H. W., Wen, Z., \& Hau, K-T. (2004). Structural equation models of latent interactions: Evaluation of alternative estimation strategies and indicator construction. Psychological Methods, 9, 275-300.

Mize, J., \& Ladd, G. W. (1988). Predicting preschoolers' peer behavior and status from their interpersonal strategies: A comparison of verbal and enactive responses to hypothetical social dilemmas. Developmental Psychology, 24, 782-788.

Mishna, F., Khoury-Kassabri, M., Gadalla, T., \& Daciuk, J. (2012). Risk factors for involvement in cyber bullying: victims, bullies and bully-victims. Children and Youth Services Review, 34, 63-70.

Mor, N., Zinbarg, R. E., Craske, M. G., Mineka, S., Uliaszek, A., Rose, R., et al. (2008). Evaluating the invariance of the factor structure of the EPQ-R-N among adolescents. Journal of Personality Assessment, 90, 66-75.

Nickerson, A. B., \& Nagle, R. J. (2005). Parent and peer attachment in late childhood and early adolescence. Journal of Early Adolescence, 25, 223 - 249.

Nikiforou, M., Georgiou, S. N., \& Stavrinides, P. (2013). Attachment to Parents and Peers as a Parameter of Bullying and Victimization. Journal of Criminology, 2013.

Ok, S., \& Aslan, S. (2010). The school bullying and perceived parental style in adolescents. Procedia Social and Behavioural Sciences, 5, 536-540.

Olweus, D. (1993). Victimization by peers: Antecedents and long-term outcomes. In K. H. Rubin \& J. B. Asendorpf (Eds). Social withdrawal, inhibition, and shyness in childhood psychology (pp. 315 - 343). Psychology Press: New York. 
Ouano, J., Buot, N. R., Conway, G. D., \& dela Rosa, E. L. (2013). A measure of the Experience of Being Bullied: An Initial Validation in Philippines Schools. Philippine Journal of Counseling Psychology, 15(1), 14-27.

Peets, K., \& Kikas, E. (2006). Aggressive strategies and victimization during adolescence: grade and gender differences, and cross- informant agreement. Aggressive Behavior, 32, 68-79.

Pepler, D., Jiang, D., Craig, W., \& Connolly, J. (2008). Developmental trajectories of bullying and associated factors. Child Development, 79, 325-338.

Perera, H. N. (2013). A novel approach to estimating and testing specific mediation effects in educational research: explication and application of Macho and Ledermann's (2011) phantom model approach. International Journal of Quantitative Research in Education, $1(1), 39-60$.

Podsakoff, P. M., MacKenzie, S. B., Lee, J. Y., \& Podsakoff, N. P. (2003). Common method biases in behavioral research: a critical review of the literature and recommended remedies. Journal of applied psychology, 88(5), 879.

Rajendran, K., Kruszewski, E., \& Halperin, J. M. (2016). Parenting styles influences bullying: a longitudinal study comparing children with and without behavioural problems. Journal of Child Psychology and Psychiatry, 57(2), 188-195.

Riebel, J., Jager, R. S., \& Fischer, U. C. (2009). Cyberbullying in Germany - an exploration of prevalence, overlapping with real life bullying and coping strategies. Psychology Science Quartely, 51, 298-314.

Rubin, K. H., Dwyer, K. M., Booth-LaForce, C., Kim, A. H., Burgess, K. B., \& Rose-Krasnor, L. (2004). Attachment, friendship, and psychosocial functioning in early adolescence. Journal of Early Adolescence, 24, 326 - 356. 
Safdar, S., \& Zahrah, S. M. (2016). Impact of parenting styles on the intensity of parental and peer attachment: exploring the gender differences in adolescents. American Journal of Applied Psychology, 4(2), 23-30.

Salmivalli, C., \& Kaukiainen, A. (2004). "Female aggression" revisited: Variable-and personcentered approaches to studying gender differences in different types of aggression. Aggressive Behavior, 30, 158-163.

Shetgiri, R., Lin, H., Avila, R., \& Flores, G. (2012). Parental characteristics associated with bullying perpetration in US children aged 10 to 17 years. Research and Practice, 102(12), 2280-2286.

Slonje, R., \& Smith, P. K. (2008). Cyberbullying: another main type of byllying? Scandinavian Journal of Psychology, 49, 147-154.

Smith, P. K., Mahdavi., J, Carvalho, M., Fisher, S., Russell, S., \& Tippett, N. (2008). Cyberbullying: its nature and impact in secondary school pupils. Journal of Child Psychology and Psychiatry, 49, 376-385.

Smith, T. D., \& McMillan, B. F. (2001). A primer of model fit indices in structural equation modelling. Paper presented at the Annual Meeting of the Southwest Educational Research Association, New Orleans, LA.

Sourander, A., Helstela, L., Helenius, H., \& Piha, J. (2000). Persistence of bullying from childhood to adolescence--a longitudinal 8-year follow-up study. Child Abuse and Neglect, 27, 873881.

Stavrinides, P., Georgiou, S., \& Theofanous, V. (2010). Bullying and empathy: A short-term longitudinal investigation. Educational Psychology, 30(7), 793-802. 
Stavrinides, P., Nikiforou, M., \& Georgiou, S. (2015). Do mothers know? Longitudinal associations between parental knowledge, bullying and victimization. Journal of Social and Personal Relationships, 32(2), 180-196.

Storch, E., \& Ledley, D. (2005). Peer victimization and psychosocial adjustment in children current knowledge and future directions. Clinical Paediatrics, 44, 29-38.

Sukkyung, Y., Furlong, M., Felix, E., Sharkey, J., \& Tanigawa, D. (2008). Relations among school connectedness, hope, life satisfaction, and bully victimization. Psychology in the Schools, $45(5), 446-460$.

Sumter, S. R., Baumgartner, S. E., Valkenburg, P. M., \& Peter, J. (2012). Developmental trajectories of peer victimization: offline and online experiences during adolescence. Journal of Adolescent Health, 50, 607-613.

Tokunaga, R. S. (2010). Following you home from school: a critical review and synthesis of research. Computers in Human Behaviour, 26, 277-287.

Valcke, M., Bonte, S., De Wever, B., \& Rots I., (2010). Internet parenting styles and the impact on Internet use of primary school children. Computers \& Education,55, 454-464.

van der Watt, R. (2014). Attachment, Parenting Styles and Bullying During Pubertal Years. Journal of Child \& Adolescent Mental Health, 26(3), 251-261.

Von Marées, N., \& Petermann, F. (2010). Gender differences, age trends and influence of parents' migration and educational backgrounds. School Psychology International, 31, 78-198.

Wang, J., Iannotti, R. J., \& Nansel, T. R. (2009). School bullying among US adolescents: Physical, verbal, relational and cyber. Journal of Adolescent Health, 45(4), 368-375.

Wang, W., Brittain, H., McDougall, P., \& Vaillancourt, T. (2016). Bullying and school transition: Context or development?. Child Abuse and Neglect, 51, 237-248. 
Wilkinson, R. B. (2004). The role of parental and peer attachment in the psychological health and self-esteem of adolescents. Journal of Youth and Adolescence, 33, 479-493.

Wilmshurst, L. (2008). Abnormal child psychology: A developmental perspective. New York: Routledge, Taylor and Francis Group.

Wolf, E. J., Harrington, K. M., Clark, S. L., \& Miller, M. W. (2013). Sample size requirements for structural equation models an evaluation of power, bias, and solution propriety. Educational and Psychological Measurement, 73(6), 913-934.

Wright, M. F., Aoyama, I., Kamble, S. V., Li, Z., Soudi, S., Lei, L., \& Shu, C. (2015). Peer attachment and cyber aggression involvement among Chinese, Indian, and Japanese adolescents. Societies, 5(2), 339-353.

Ybarra, M. M., \& Mitchell, K. J. (2004). Youth engaging in online harassment: associations with caregiver-child relationships, Internet use, and personal characteristics. Journal of Adolescence, 27, 319-336. 


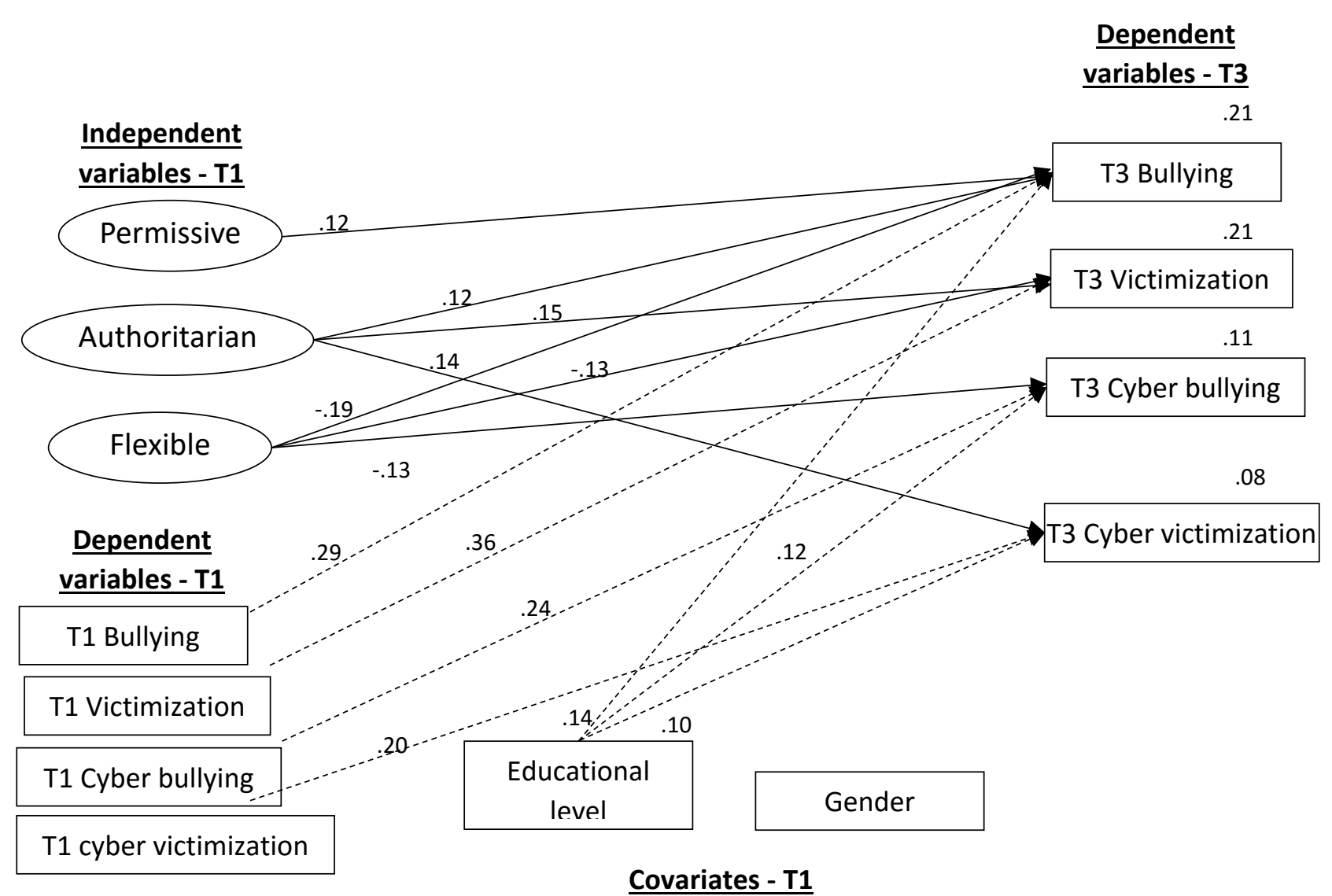

Figure 1. The structural part of Model 1 along with regression and multiple correlation coefficients. Only significant effects are depicted. All coefficients shown are standardised and significant at $p<$ 0.05 . Values associated with single-headed arrows represent standardised regression coefficients. Dashed lined represent covariate effects. Values placed over endogenous variables represent squared multiple correlations. 


\section{Mediators - T2}

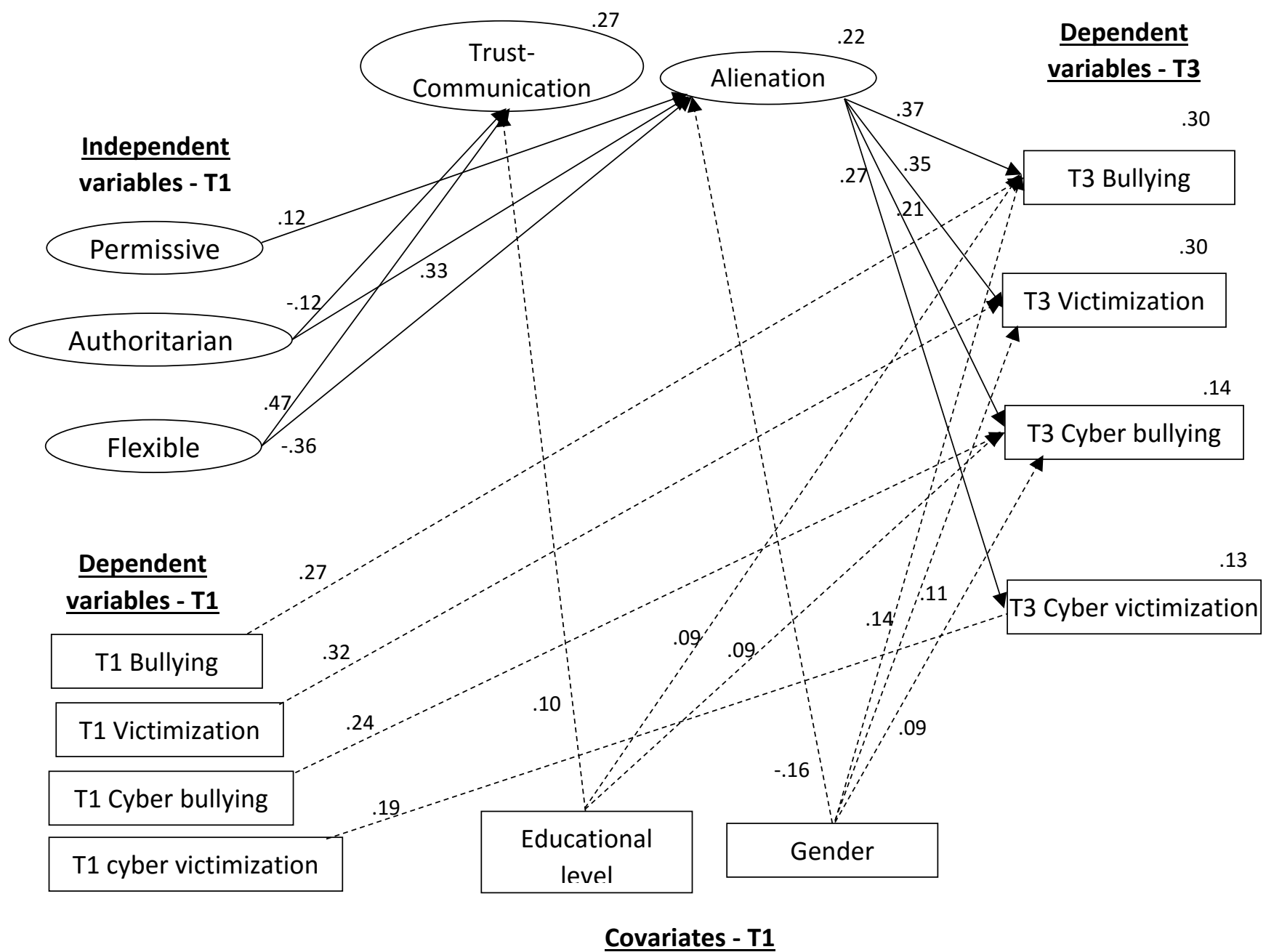

Figure 2. The structural part of Model 2 along with regression and multiple correlation coefficients. Only significant effects are depicted. All coefficients shown are standardised and significant at $p<$ 0.05 . Values associated with single-headed arrows represent standardised regression coefficients. Values placed over endogenous and mediating variables represent squared multiple correlations. 


\section{Appendix A}

Item loadings, means, standard deviations, skewness, kurtosis and item-total correlation per factor, regarding the EFA results of the PAQ questionnaire

\begin{tabular}{|c|c|c|c|c|c|c|c|c|}
\hline \multirow[b]{2}{*}{ Item stem } & \multicolumn{3}{|c|}{ Factor loadings ${ }^{\mathrm{a}}$} & \multirow[b]{2}{*}{ M } & \multirow[b]{2}{*}{$\mathrm{SD}$} & \multirow[b]{2}{*}{ Sk. } & \multirow[b]{2}{*}{ Kurt. } & \multirow{2}{*}{$\begin{array}{c}\text { Item } \\
- \\
\text { total } \\
\text { corr }\end{array}$} \\
\hline & 1 & 2 & 3 & & & & & \\
\hline $\begin{array}{l}\text { My mother consistently gives me direction and guidance in } \\
\text { rational and objective ways........................................... }\end{array}$ & .73 & & & 4.13 & 1.13 & -1.13 & .36 & .55 \\
\hline $\begin{array}{l}\text { My mother gives me direction for my behavior, but she is } \\
\text { always willing to listen to my concerns............................ }\end{array}$ & .70 & & & 4.17 & 1.18 & -1.20 & .27 & .62 \\
\hline 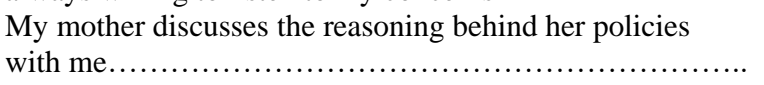 & .63 & & & 3.99 & 1.23 & -.97 & -.19 & .54 \\
\hline $\begin{array}{l}\text { My mother directs her decisions with me through } \\
\text { reasoning }\end{array}$ & .61 & & & 4.05 & 1.19 & -.97 & -.25 & .50 \\
\hline $\begin{array}{l}\text { I know what my mother expects of me, but I also feel free } \\
\text { to discuss those expectations with her. }\end{array}$ & .59 & & & 4.12 & 1.19 & -1.20 & .39 & .52 \\
\hline 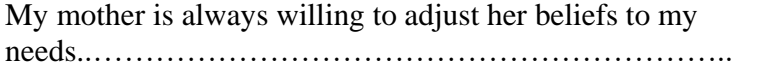 & .56 & & & 3.88 & 1.24 & -.87 & -.36 & .50 \\
\hline $\begin{array}{l}\text { My mother gives me clear direction for my behaviors, but } \\
\text { she was also understanding when I disagreed with her........ }\end{array}$ & .54 & & & 3.55 & 1.35 & -.47 & -1.00 & .48 \\
\hline My mother is willing to admit it if she has made a mistake.. & .47 & & & 3.88 & 1.29 & -.77 & -.73 & .50 \\
\hline $\begin{array}{l}\text { My mother takes my opinion into consideration when } \\
\text { making family decisions................................................ }\end{array}$ & .46 & & & 3.48 & 1.30 & -.32 & -1.04 & .51 \\
\hline $\begin{array}{l}\text { My mother always encourages verbal give-and-take } \\
\text { whenever I feel that family rules and restrictions are } \\
\text { unreasonable.............................................................. }\end{array}$ & .42 & & & 3.43 & 1.48 & -.43 & -1.23 & .45 \\
\hline $\begin{array}{l}\text { Whenever my mother tells me to do something, she expects } \\
\text { me to do it immediately without asking any questions....... }\end{array}$ & & .62 & & 2.21 & 1.34 & .88 & -.47 & .57 \\
\hline $\begin{array}{l}\text { My mother forces me to conform to what she thinks is } \\
\text { right... }\end{array}$ & & .62 & & 2.25 & 1.40 & .80 & -.71 & .58 \\
\hline My mother gets very upset if I try to disagree with her....... & & .61 & & 2.06 & 1.20 & 1.07 & .19 & .53 \\
\hline $\begin{array}{l}\text { My mother does not allow me to question any decision she } \\
\text { has made }\end{array}$ & & .57 & & 1.99 & 1.21 & 1.19 & .45 & .49 \\
\hline $\begin{array}{l}\text { My mother has always felt that parents should force their } \\
\text { children to behave the way they are supposed to.................. }\end{array}$ & & .56 & & 3.06 & 1.52 & .01 & -1.49 & .44 \\
\hline $\begin{array}{l}\text { My mother felt that wise parents should teach their } \\
\text { children early who is boss in the family................ }\end{array}$ & & .56 & & 2.28 & 1.44 & .80 & -.74 & .45 \\
\hline My mother is strict to me.......................................... & & .55 & & 2.08 & 1.10 & 1.01 & .48 & .50 \\
\hline If I brake a rule, my mother punishes me....................... & & .47 & & 2.18 & 1.23 & .86 & -.22 & .40 \\
\hline $\begin{array}{l}\text { My mother often tells me exactly what she wants me to do } \\
\text { and how she expects me to do it.......................................... }\end{array}$ & & .46 & & 3.03 & 1.36 & .07 & -1.24 & .43 \\
\hline $\begin{array}{l}\text { My mother expects me to conform to her expectations } \\
\text { simply out of respect for her authority ......................... }\end{array}$ & & .41 & & 2.35 & 1.38 & .72 & -.76 & .37 \\
\hline My mother allows me to decide most things for myself....... & & & .62 & 2.87 & 1.24 & .27 & -1.01 & .39 \\
\hline $\begin{array}{l}\text { My mother allows me to decide for myself what I am going } \\
\text { to do }\end{array}$ & & & .62 & 2.97 & 1.37 & .14 & -.98 & .36 \\
\hline 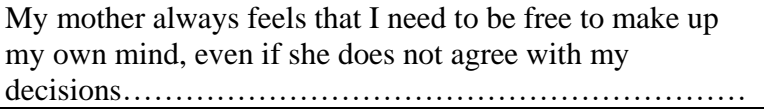 & & & .53 & 2.43 & 1.42 & .06 & -1.21 & .24 \\
\hline
\end{tabular}

${ }^{a}$ Loadings $<.04$ are omitted; M: mean, SD: standard deviation, Sk.: skewness, Kurt.: Kurtosis, Item-total corr.: Item-total correlation. 


\section{Appendix B}

Item loadings, means, standard deviations, skewness, kurtosis and item-total correlation per factor, regarding the EFA results of the IPPA questionnaire

\begin{tabular}{|c|c|c|c|c|c|c|c|}
\hline \multirow{2}{*}{ Item stem } & \multicolumn{2}{|c|}{$\begin{array}{c}\text { Factor } \\
\text { loadings }\end{array}$} & \multirow{2}{*}{ M } & \multirow{2}{*}{$\mathrm{SD}$} & \multirow{2}{*}{ Sk. } & \multirow{2}{*}{ Kurt. } & \multirow{2}{*}{$\begin{array}{l}\text { Item- } \\
\text { total } \\
\text { corr. }\end{array}$} \\
\hline & 1 & 2 & & & & & \\
\hline My friends are fairly easy to talk to... & .78 & & 3.92 & 1.26 & -.98 & -.10 & .67 \\
\hline My friends respect my feelings... & .75 & & 4.09 & 1.18 & -1.27 & .71 & .77 \\
\hline 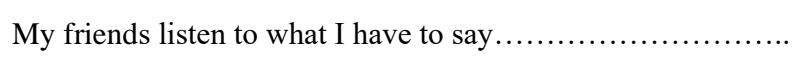 & .75 & & 4.16 & 1.17 & -1.42 & 1.09 & .73 \\
\hline 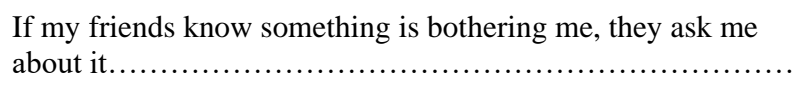 & .74 & & 3.87 & 1.25 & -.91 & -.20 & .65 \\
\hline I can tell my friends about my problems and troubles............ & .72 & & 3.60 & 1.32 & -.61 & -.79 & .66 \\
\hline $\begin{array}{l}\text { When we discuss things, my friends care about my point of } \\
\text { view }\end{array}$ & .72 & & 3.86 & 1.22 & -.92 & -.11 & 67 \\
\hline $\begin{array}{l}\text { When I am angry about something, my friends try to be } \\
\text { understanding....................................................... }\end{array}$ & .71 & & 3.91 & 1.22 & -.94 & -.12 & .70 \\
\hline My friends understand me ..................................... & .71 & & 4.15 & 1.13 & -1.29 & .73 & .69 \\
\hline My friends help me to understand myself better.................... & .70 & & 3.71 & 1.29 & -.78 & -.46 & .63 \\
\hline My friends encourage me to talk about my difficulties.......... & 69 & & 3.58 & 1.35 & -.64 & -.75 & .66 \\
\hline 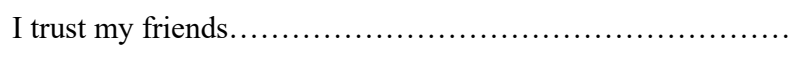 & .66 & & 4.22 & 1.12 & -1.32 & .75 & .67 \\
\hline $\begin{array}{l}\text { I like to get my friend's point of view on things I'm concerned } \\
\text { about. }\end{array}$ & .64 & & 3.76 & 1.32 & -.83 & -.45 & .49 \\
\hline 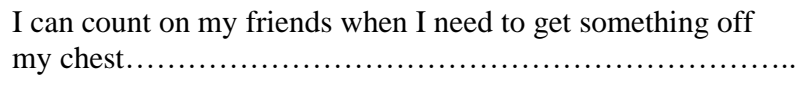 & .63 & & 3.80 & 1.34 & -.91 & -.38 & .63 \\
\hline 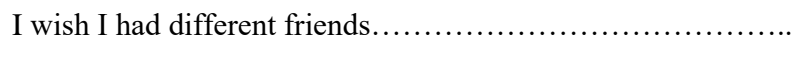 & & .66 & 1.41 & .94 & 2.54 & 5.87 & .49 \\
\hline I feel angry with my friends. & & .63 & 1.67 & 1.01 & 1.78 & 2.90 & .47 \\
\hline It seems as if my friends are irritated with me for no reason.... & & .58 & 1.47 & .86 & 2.19 & 4.84 & .49 \\
\hline 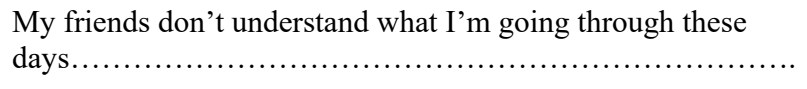 & & .58 & 1.42 & .91 & 2.45 & 5.69 & .50 \\
\hline I get upset a lot more than my friends know about................ & & .53 & 2.37 & 1.38 & .70 & -.76 & .37 \\
\hline 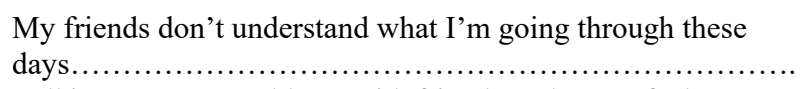 & & .42 & 2.27 & 1.42 & .76 & -.85 & .28 \\
\hline $\begin{array}{l}\text { Talking over my problems with friends makes me feel } \\
\text { ashamed or foolish } \ldots \ldots \ldots \ldots \ldots \ldots \ldots \ldots \ldots \ldots \ldots \ldots \ldots \ldots \ldots \ldots\end{array}$ & & $.36^{\mathrm{b}}$ & 1.80 & 1.09 & 1.48 & 1.57 & .31 \\
\hline
\end{tabular}

${ }^{\mathrm{a}}$ Loadings $<.04$ are omitted; ${ }^{\mathrm{b}} \mathrm{Q} 4$ item was retained despite its low loading because it contributed to the subscales' internal consistency. M: mean, SD: standard deviation, Sk.: skewness, Kurt.: Kurtosis, Item-total corr.: Item-total correlation. 